\title{
Investigation of long-term survival outcomes and failure patterns of patients with nasopharyngeal carcinoma receiving intensity-modulated radiotherapy: a retrospective analysis
}

\author{
Wei Zhao ${ }^{1, *}$, Hao Lei ${ }^{1,2, *}$, Xiaodong Zhu ${ }^{1}$, Ling Li ${ }^{1}$, Song Qu ${ }^{1}$, Xia Liang ${ }^{1}$ \\ ${ }^{1}$ Department of Radiation Oncology, Cancer Hospital of Guangxi Medical University, Nanning, 530021, China \\ ${ }^{2}$ Department of Radiation Oncology, Hubei Cancer Hospital, Wuhan, 430079, China \\ *Wei Zhao and Hao Lei are co-first authors \\ Correspondence to: Xiaodong Zhu, email: zhuxidonggxmu@126.com \\ Keywords: failure pattern, intensity-modulated radiotherapy, long-term outcome, nasopharyngeal carcinoma, retrospective analysis \\ Received: August 16, 2016 \\ Accepted: November 07, 2016 \\ Published: November 24, 2016
}

\section{ABSTRACT}

Intensity-modulated radiotherapy (IMRT) has replaced the conventional radiotherapy (2D-RT) and improved clinical efficacy in Nasopharyngeal Carcinoma (NPC) patients. In the present study, we retrospectively analyzed the clinical characteristics of patients with NPC treated with IMRT to assess the long-term survival outcomes and failure patterns. Of the 527 patients, One hundred and twenty-one patients experienced treatment failure, 86 patients developed distant metastases, and 12 patients developed a second primary tumor. The local and regional recurrence rates were $31.4 \%$ and $14.0 \%$, respectively. The 5 -year overall survival (OS), progression-free survival (PFS), local recurrence-free survival (LRFS), regional relapse-free survival (RRFS), and distant metastatic relapse-free survival (DMFS) rates were $80.9 \%, 75.6 \%, 91.7 \%, 96.2 \%$, and $83.0 \%$, respectively. The 5-year LRFS rates of Stage T1-4 patients were $100.0 \%, 93.1 \%, 92.0 \%$, and $85.8 \%$, respectively. The 5-year DMFS rates of Stage N0-3 patients were $95.0 \%, 86.1 \%, 79.5 \%$, and $67.2 \%$, respectively. Multivariate analysis showed age and T-stage were independent predictors of OS, T-stage was an independent predictor of LRFS, and age and $\mathrm{N}$-stage were independent predictors of PFS and DMFS.

In summary, the improved treatment results with IMRT are primarily due to the achievement of a higher local tumor control rate and OS in NPC patients. However, distant metastasis was the most commonly observed failure pattern after treatment. These results provide deep insights about the value of IMRT in the treatment and prognosis of NPC patients.

\section{INTRODUCTION}

NPC is the most common malignant head and neck tumor in Asian patients, particularly in southern China. Considering the high sensitivity of radiotherapy, IMRT has exhibited improved clinical efficacy in NPC patients, and has hence widely replaced the conventional radiotherapy, including two-dimensional radiation therapy technology and three-dimensional conformal radiotherapy technology. From 1996 to 2000, the 5-year OS of 2,687 patients who underwent conventional two-dimensional radiotherapy was $75 \%$ [1]. Moreover, the 5-year disease- specific survival rate (2005-2010) of 444 patients treated with IMRT was approximately $85 \%$ [2]. Thus, IMRT has become the standard technology for the treatment of NPC for improving local control and protecting the surrounding normal tissue. However, to our knowledge, studies with a large sample, long-term follow-up, and various disease stages among patients with NPC are rare. In the present study, we retrospectively analyzed the clinical characteristics of patients with biopsy-proven, non-metastatic NPC treated with IMRT from January 2007 to December 2011 in our hospital to assess the long-term survival outcomes and failure patterns. 


\section{RESULTS}

\section{Follow-up results}

At the end of the study period, the follow-up rate was 98.3\% and median follow-up time was 38 months (range, 4-97 months). Moreover, 18.4\% (97/527) patients died, $23.0 \%(121 / 527)$ exhibited treatment failure, and 2.3\% $(12 / 527)$ developed second primary tumors (SPTs) SPTs. Among the patients with treatment failure, 71.1\% (86/121) developed distant metastasis, 31.4\% (38/121) developed local recurrence, and $14.0 \%$ (17/121) developed regional lymph node recurrence, $57.0 \%$ (69/121) developed simple distant metastasis (median failure duration, 14 months), $21.5 \%$ (26/121) developed simple local recurrence (median failure duration, 23.5 months), 7.4\% (9/121) developed both local recurrence and metastasis (median failure duration, 19 months), 5.8\% (7/121) developed regional lymph node recurrence (median failure duration, 34 months), 5.8\% (7/121) developed both local recurrence and metastasis (median failure duration, 9 months), 1.7\% $(2 / 121)$ developed both regional lymph node recurrence and local recurrence (median failure duration, 14 months), and $0.8 \%$ (1/121) developed regional lymph node recurrence, local recurrence, and metastasis (median failure duration, 22 months).

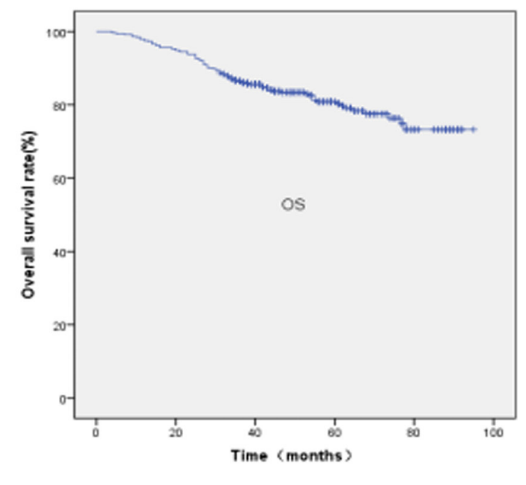

$1-1$

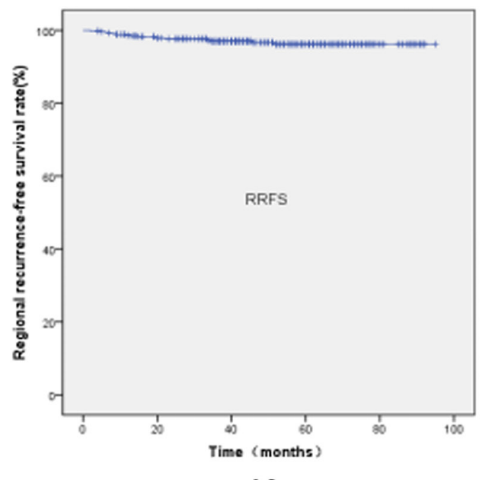

$1-3$

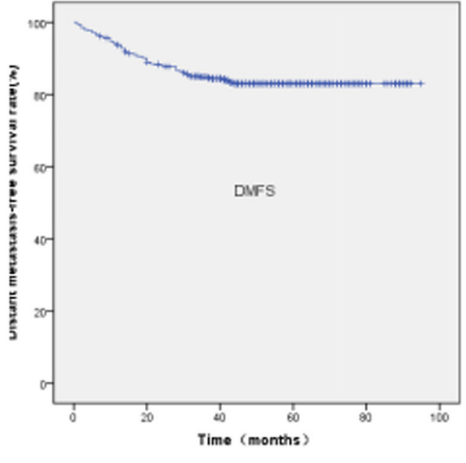

$1-4$

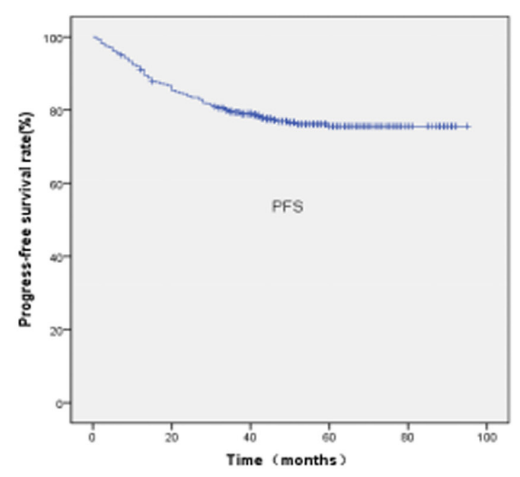

1-2

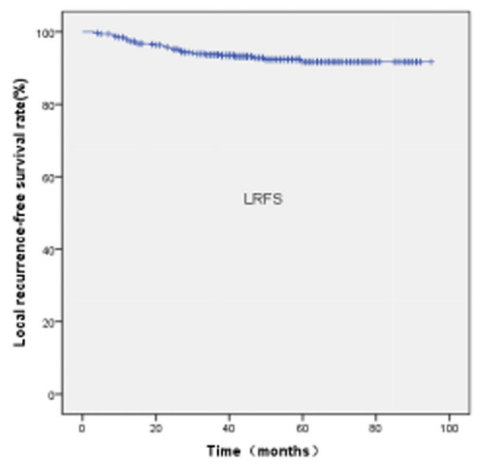

$1-5$

Figure 1: Kaplan-Meier survival curves for the overall survival (1-1), progression-free survival (1-2), regional recurrence-free survival (1-4), distant metastasis-free survival (1-5), and local recurrence-free survival (1-3) rate of all the patients with nasopharyngeal carcinoma. 
significantly different. However, The 5-year DMFS rates between stage $\mathrm{N} 0$ and $\mathrm{N} 2\left(\chi^{2}=7.703, \mathrm{P}=0.006\right)$, stage N0 and $\mathrm{N} 3\left(\chi^{2}=12.659, \mathrm{P}=0.000\right)$, stage $\mathrm{N} 1$ and $\mathrm{N} 2\left(\chi^{2}=4.908\right.$, $\mathrm{P}=0.027)$, and stage $\mathrm{N} 1$ and $\mathrm{N} 3\left(\chi^{2}=8.022, \mathrm{P}=0.005\right)$ were significantly different. The DMFS survival curves of different $\mathrm{N}$ stages are shown in Figure 3.

\section{Analysis of prognostic factors}

Univariate analysis revealed that the application of concurrent, neoadjuvant, and adjuvant chemotherapy did not significantly improve the prognosis of patients. In particular, the $\mathrm{T}$ stage and clinical stage were factors that

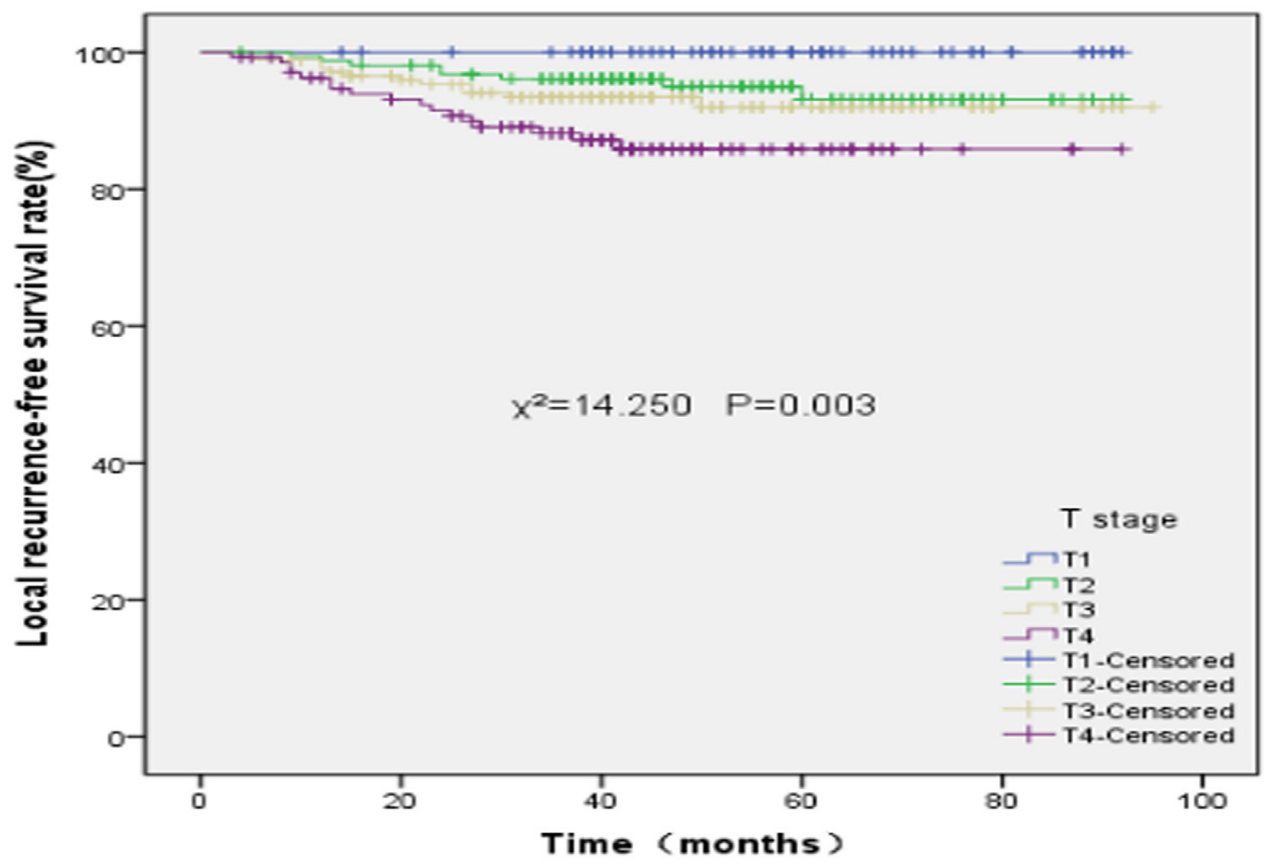

Figure 2: Local recurrence-free survival rates of 527 patients with nasopharyngeal carcinoma at different $\mathbf{T}$ stages.

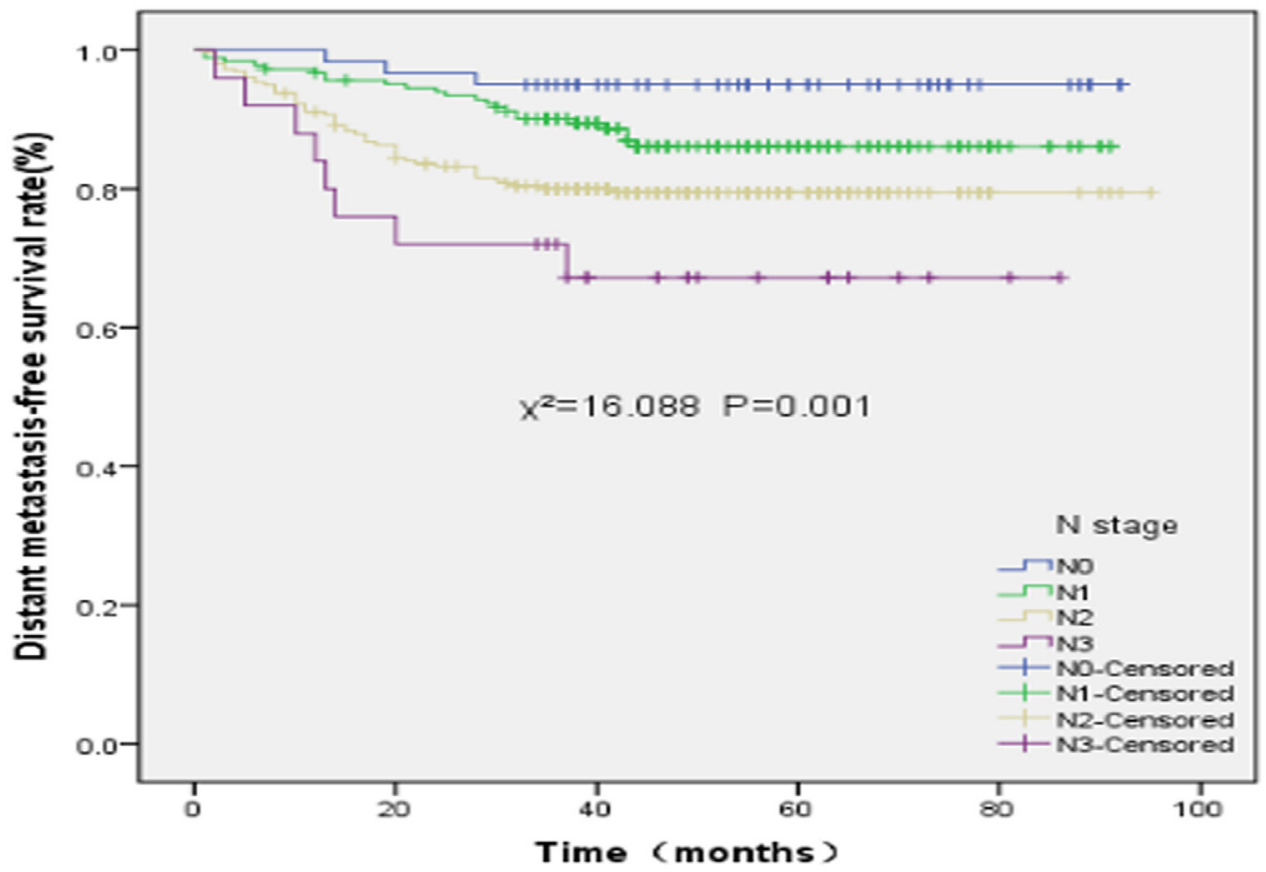

Figure 3: Distant metastasis-free survival rates of 527 patients with nasopharyngeal carcinoma at different $\mathbf{N}$ stages 
Table 1: Univariate analysis of various clinical endpoints

\begin{tabular}{|c|c|c|c|c|c|c|c|c|c|c|c|c|c|c|c|c|}
\hline Characteristic & $\mathbf{N}$ & $\begin{array}{l}\text { 5-year } \\
\text { LRFS }\end{array}$ & $\chi^{2}$ & $P$ & $\begin{array}{l}\text { 5-year } \\
\text { RRFS }\end{array}$ & $\chi^{2}$ & $P$ & $\begin{array}{l}\text { 5-year } \\
\text { DMFS }\end{array}$ & $\chi^{2}$ & $P$ & $\begin{array}{l}\text { 5-year } \\
\text { OS }\end{array}$ & $\chi^{2}$ & $P$ & $\begin{array}{l}\text { 5-year } \\
\text { PFS }\end{array}$ & $\chi^{2}$ & $P$ \\
\hline Sex & & & 0.438 & 0.508 & & 0.648 & 0.421 & & 1.904 & 0.168 & & 1.733 & 0.188 & & 2.809 & 0.094 \\
\hline Male & 394 & 91.2 & & & 95.9 & & & 81.9 & & & 78.9 & & & 73.9 & & \\
\hline Female & 133 & 93.2 & & & 97.1 & & & 86.4 & & & 86.4 & & & 80.3 & & \\
\hline Age (years) & & & 2.505 & 0.114 & & 0.890 & 0.452 & & 4.317 & 0.038 & & 10.275 & 0.001 & & 4.844 & 0.028 \\
\hline$\leq 44$ & 255 & 93.9 & & & 95.2 & & & 86.4 & & & 85.6 & & & 79.6 & & \\
\hline$>44$ & 272 & 89.1 & & & 97.5 & & & 79.3 & & & 75.7 & & & 71.3 & & \\
\hline T stage & & & 14.250 & 0.003 & & 0.984 & 0.805 & & 11.975 & 0.007 & & 22.287 & 0.000 & & 20.965 & 0.000 \\
\hline $\mathrm{T} 1$ & 62 & 100.0 & & & 97.6 & & & 93.5 & & & 93.3 & & & 91.2 & & \\
\hline $\mathrm{T} 2$ & 156 & 93.1 & & & 96.2 & & & 85.8 & & & 86.8 & & & 77.5 & & \\
\hline $\mathrm{T} 3$ & 174 & 92.0 & & & 96.5 & & & 83.2 & & & 80.2 & & & 77.4 & & \\
\hline $\mathrm{T} 4$ & 135 & 85.8 & & & 96.0 & & & 74.7 & & & 65.8 & & & 64.5 & & \\
\hline N stage & & & 5.375 & 0.146 & & 2.686 & 0.443 & & 16.088 & 0.001 & & 14.285 & 0.003 & & 22.575 & 0.000 \\
\hline No & 60 & 94.7 & & & 100.0 & & & 95.0 & & & 90.6 & & & 89.8 & & \\
\hline N1 & 184 & 94.4 & & & 96.0 & & & 86.1 & & & 81.4 & & & 80.7 & & \\
\hline $\mathrm{N} 2$ & 258 & 91.1 & & & 95.3 & & & 79.5 & & & 79.3 & & & 71.7 & & \\
\hline $\mathrm{N} 3$ & 25 & 71.4 & & & 95.7 & & & 67.2 & & & 67.8 & & & 44.8 & & \\
\hline Clinical stage & & & 12.482 & 0.006 & & 1.230 & 0.746 & & 20.046 & 0.000 & & 27.607 & 0.000 & & 28.673 & 0.000 \\
\hline I & 18 & 100.0 & & & 100.0 & & & 100.0 & & & 100.0 & & & 100.0 & & \\
\hline II & 111 & 95.5 & & & 95.8 & & & 91.0 & & & 87.4 & & & 84.3 & & \\
\hline III & 245 & 94.0 & & & 96.5 & & & 84.4 & & & 84.3 & & & 79.0 & & \\
\hline Iva-b & 153 & 82.1 & & & 95.7 & & & 73.0 & & & 67.1 & & & 59.8 & & \\
\hline $\begin{array}{l}\text { Concurrent } \\
\text { chemotherapy }\end{array}$ & & & 1.535 & 0.215 & & 0.922 & 0.337 & & 0.728 & 0.394 & & 0.226 & 0.635 & & 0.570 & 0.450 \\
\hline No & 77 & 95.9 & & & 94.6 & & & 86.4 & & & 80.9 & & & 79.9 & & \\
\hline Yes & 450 & 90.7 & & & 96.4 & & & 82.5 & & & 80.8 & & & 74.6 & & \\
\hline
\end{tabular}

OS, overall survival;PFS, progression-free survival; LRFS, local recurrence-free survival;RRFS, regional recurrence-free survival, DMFS, distant metastasis-free survival

independently influenced the LRFS rate. Moreover, age, $\mathrm{T}$ stage, $\mathrm{N}$ stage, and clinical stage were the factors that independently influenced the DMFS, OS, and PFS rates (Table 1). Multiple factor analysis indicated that age and T stage independently influenced OS; T stage independently influenced LRFS; and age and $\mathrm{N}$ stage independently influenced DMFS and PFS (Table 2).

A total of 38 cases exhibited local recurrence, including 37 with complete nasopharyngeal and neck MRI data of both primary and recurrent NPC. The most common location of the primary NPC was the nasopharyngeal space, parapharyngeal space, and skull base, in that order. Moreover, the most common sites of recurrence of NPC after treatment with IMRT were the nasopharyngeal space, skull base, and parapharyngeal space, in that order. The differences in the location of invasion with primary and recurrent NPC are shown in Table 3.

\section{Analysis of regional lymph node recurrence}

A total of 17 cases exhibited regional lymph node recurrence; all these patients had complete nasopharyngeal and neck MRI data of the primary and recurrent NPC. These MRI data indicated that the rate of invasion of level I lymph nodes in both primary and recurrent cases was $23.5 \%$ (4/17), whereas the rate of invasion of level II lymph nodes in primary and recurrent cases were $100 \%(17 / 17)$ and $64.7 \%(11 / 17)$, respectively. In primary and recurrent cases, the rates of invasion of level III lymph nodes were 58.8\% (10/17) and 23.5\% (4/17); those of level IV lymph nodes were $29.4 \%(5 / 17)$ and $0 \%(0 / 17)$; those of level V lymph nodes were both $11.8 \%(2 / 17)$; and those of parotid lymph nodes were $0 \%(0 / 17)$ and $11.8 \%(2 / 17)$, respectively. In addition, the most common invasion sites of primary tumors included level II and level III lymph nodes, whereas the most common invasion sites of recurrent cases included level 
Table 2: Multivariate analysis of various clinical endpoints.

\begin{tabular}{|c|c|c|c|c|}
\hline \multirow{2}{*}{ Variable } & \multirow{2}{*}{ HR } & \multicolumn{2}{|c|}{$95 \% \mathrm{CI}$} & \multirow{2}{*}{$P$} \\
\hline & & Lower & Upper & \\
\hline \multicolumn{5}{|l|}{ LRFS } \\
\hline T stage & 3.676 & 1.093 & 12.366 & 0.035 \\
\hline \multicolumn{5}{|l|}{ DMFS } \\
\hline Age & 1.584 & 1.025 & 2.446 & 0.038 \\
\hline N stage & 1.803 & 1.025 & 3.173 & 0.041 \\
\hline \multicolumn{5}{|l|}{ OS } \\
\hline Age & 1.887 & 1.243 & 2.865 & 0.003 \\
\hline T stage & 2.131 & 1.153 & 3.940 & 0.016 \\
\hline \multicolumn{5}{|l|}{ PFS } \\
\hline Age & 1.500 & 1.039 & 2.165 & 0.030 \\
\hline $\mathrm{N}$ stage & 2.009 & 1.230 & 3.282 & 0.005 \\
\hline
\end{tabular}

OS, overall survival; PFS, progression-free survival; LRFS, local recurrence-free survival; RRFS, regional recurrence-free survival, DMFS, distant metastasis-free survival; CI, confidence interval

Table 3: Comparison of tumor invasion in adjacent regions between pNPC and rNPC

\begin{tabular}{|c|c|c|c|c|c|}
\hline Tumor invasion site & $\begin{array}{c}\text { Invasion in } \\
\text { pNPC and rNPC } \\
\text { (number) }\end{array}$ & $\begin{array}{l}\text { Invasion in } \\
\text { pNPC alone } \\
\text { (number) }\end{array}$ & $\begin{array}{l}\text { Invasion in } \\
\text { rNPC alone } \\
\text { (number) }\end{array}$ & $\begin{array}{l}\text { No invasion in } \\
\text { pNPC or rNPC } \\
\text { (number) }\end{array}$ & $P$ \\
\hline Nasopharynx & 29 & 8 & 0 & 0 & 0.008 \\
\hline Oropharynx & 1 & 2 & 0 & 34 & 0.500 \\
\hline Nasal cavity & 4 & 5 & 3 & 25 & 0.727 \\
\hline Parapharyngeal space & 10 & 22 & 0 & 5 & $<0.001$ \\
\hline Skull base & 19 & 9 & 2 & 7 & 0.065 \\
\hline Paranasal sinus & 5 & 5 & 6 & 21 & 1.000 \\
\hline Intracranial cavity & 7 & 4 & 2 & 24 & 0.687 \\
\hline Infratemporal fossa & 1 & 2 & 0 & 34 & 0.500 \\
\hline Laryngopharynx & 0 & 0 & 1 & 36 & 1.000 \\
\hline Orbital apex & 0 & 2 & 1 & 34 & 1.000 \\
\hline Masticatory muscles & 1 & 7 & 2 & 27 & 0.180 \\
\hline
\end{tabular}

Abbreviation: $\mathrm{pNPC}=$ primary nasopharyngeal carcinoma, $\mathrm{rNPC}=$ recurrent nasopharyngeal carcinoma

II, III, and I lymph nodes. The distribution of the sites of invasion among the lymph nodes in cases of primary and recurrent NPC are shown in Table 4.

\section{Characteristics of distant metastases}

A total of 86 cases exhibited distant metastasis, including $43.0 \%(37 / 86)$ with bone metastasis, $41.9 \%$ (36/86) with lung metastasis, $31.4 \%$ (27/86) with liver metastasis, $17.4 \%(15 / 86)$ with metastasis in the mediastinal lymph nodes, $11.6 \%(10 / 86)$ with metastasis in the abdominal lymph nodes, $2.3 \%$ (2/86) with metastasis in the axillary lymph node, $5.8 \%(5 / 86)$ with metastasis in the brain, and $1.2 \%(1 / 86)$ with metastasis in the pancreas, pericardium, and kidney. Among the cases with metastasis, most of the patients with mediastinal lymph node metastasis also showed lung metastasis, and all the patients with abdominal lymph node metastasis also showed liver metastasis. The characteristics of distant metastasis are shown in Table 5. 
Table 4: Comparison of tumor invasion in lymph nodes between pNPC and rNPC

\begin{tabular}{lccccc}
\hline Node invasion site & $\begin{array}{c}\text { Invasion in } \\
\text { pNPC and rNPC } \\
\text { (number) }\end{array}$ & $\begin{array}{c}\text { Invasion in } \\
\text { pNPC alone } \\
\text { (number) }\end{array}$ & $\begin{array}{c}\text { Invasion in } \\
\text { rNPC alone } \\
\text { (number) }\end{array}$ & $\begin{array}{c}\text { No invasion in } \\
\text { pNPC or rNPC } \\
\text { (number) }\end{array}$ \\
\hline I & 1 & 3 & 3 & 10 & 1.000 \\
II & 11 & 6 & 0 & 0 & 0.031 \\
III & 4 & 6 & 0 & 1 & 0.031 \\
IV & 0 & 5 & 0 & 12 & 0.063 \\
V & 1 & 1 & 14 & 1.000 \\
\hline
\end{tabular}

pNPC, primary nasopharyngeal carcinoma; rNPC, recurrent nasopharyngeal carcinoma

Table 5: Characteristics of distant metastasis

\begin{tabular}{lcccc}
\hline Site & \multicolumn{1}{c}{ Total } & Disease incidence & Single organ & Multiple organs \\
\hline Bone & $43.0 \%(37 / 86)$ & $7.0 \%(37 / 527)$ & 19 & 17 \\
Lung & $41.9 \%(36 / 86)$ & $6.8 \%(36 / 527)$ & 13 & 19 \\
Liver & $31.4 \%(27 / 86)$ & $5.1 \%(27 / 527)$ & 2 & 14 \\
Mediastinal lymph & $17.4 \%(15 / 86)$ & $2.8 \%(15 / 527)$ & & \\
nodes & $11.6 \%(10 / 86)$ & $1.9 \%(10 / 527)$ & 0 & 13 \\
Abdominal lymph & $2.3 \%(2 / 86)$ & $0.4 \%(2 / 527)$ & 1 & 1 \\
nodes & $5.8 \%(5 / 86)$ & $0.9 \%(5 / 527)$ & 3 & \\
Axillary lymph node & $1.2 \%(1 / 86)$ & $0.2 \%(1 / 527)$ & 0 & 1 \\
Brain & $1.2 \%(1 / 86)$ & $0.2 \%(1 / 527)$ & 0 & 1 \\
Pancreas & $1.2 \%(1 / 86)$ & $0.2 \%(1 / 527)$ & 0 & 1 \\
Kidney & & & \\
Pericardium & & & \\
\hline
\end{tabular}

\section{DISCUSSION}

Since it was first clinically introduced in 1990, IMRT has become the first-choice treatment option for the treatment of NPC. In a recent study, Sun et al retrospectively analyzed 868 patients with NPC treated with IMRT, wherein approximately $69.4 \%$ patients had phase III-IVa disease, and found that the 5-year Disease Specific Survival (DSS), LRFS, RRFS, DMFS, and PFS rates were $84.7 \%, 91.8 \%, 96.4 \%, 91.8 \%$, and $77.0 \%$, respectively [3]. In the present study, the proportion of patients with phase III-IVa-b disease was approximately $75.5 \%$, and the 5-year OS, LRFS, RRFS, DMFS, and PFS rates were $80.9 \%, 91.7 \%, 96.2 \%, 91.7 \%$, and $75.6 \%$, respectively. Compared with the results of a study on non-IMRT treatment options in our hospital [4], which are similar to those of studies in other research centers [2, $5,6]$, the present study indicated that IMRT significantly improved the patient's OS, LRFS, and PFS. Moreover, our study indicated that distant metastasis was the most common cause of treatment failure in patients with NPC, followed by local recurrence and regional lymph node recurrence. Although previous studies on IMRT have reported similar results $[33,7,8]$, studies on conventional radiotherapy of NPC have indicated that local recurrence is the main reason for treatment failure $[1,5,6]$. Moreover, we observed that 12 patients with NPC developed SPTs after treatment. In addition, in studies on conventional radiotherapy, the incidence of SPTs was approximately $2.0-5.2 \%$ [9-12]. Hence, the incidence of SPTs induced by IMRT and conventional radiotherapy is similar. However, as the follow-up duration of the preset study was relatively short and the incidence of SPTs would increase with an increase in the follow-up duration, physicians should carefully consider the development of SPTs after treatment with IMRT.

Due to the presence of a dose-effect relationship between local control and exposure dose in NPC, the enhancement of the irradiation dose to the tumor could improve the local control rates of patients. Compared to the results of conventional two-dimensional radiotherapy $[1,5,6]$, the present study indicated that IMRT 
significantly improved the local control rate of patients with NPC; in fact, the local control rate would also benefit from the enhancement of the irradiation dose in the tumor and high-risk regions. Furthermore, our study showed that there was no significant difference in the LRFS rate between patients with stage $\mathrm{T} 1$ and $\mathrm{T} 2$ disease, stage T2 and $\mathrm{T} 3$ disease, and stage $\mathrm{T} 3$ and $\mathrm{T} 4$ disease. In a study of 985 NPC patients who underwent IMRT, Lee et al showed that there was no significant difference in the LRFS rate between patients with stage $\mathrm{T} 1$ and $\mathrm{T} 2$ disease [13]. Moreover, Chen et al did not show any significant difference in the LRFS rate between stage T2 and T3 patients treated with IMRT [14]. Similarly, a study of 1241 patients treated with IMRT revealed that there was no significant difference in the LRFS rate between stage $\mathrm{T} 1$ and T2, and stage T2 and T3 patients [15]. Despite the differences in the sample size and follow-up duration in the above-mentioned studies, the improvement of the treatment effect as a result of advancements in irradiation technology should not be neglected, particularly in terms of dose enhancement in IMRT as compared to doserestricted areas (e.g., retropharyngeal space, skull base, etc.) in conventional two-dimensional radiotherapy [16]. Therefore, we believe that the reason for the lack of a significant difference in the LRFS rates between adjacent T stages is a result of the improvement of dose application with IMRT as compared to dose-restricted areas in conventional 2D-RT, which is not completely reflected in the 2010 Union for International Cancer Control (UICC) staging system.

The present study indicated that the nasopharynx (78.4\%) and skull base (57.8\%) are the most common sites of recurrence, followed by the parapharyngeal space, intracranial region, paranasal sinus, nasal cavity, chewing muscles, region below the temporal fossa, orbit, and oropharynx, with rates $<10 \%$. This result is similar to that of the study of $\mathrm{Li}$ [17] and $\mathrm{Ng}$ [18] who showed that the recurrence rates in the nasopharynx and skull base of NPC patients after IMRT were approximately $78.1 \%$ and $59.4 \%$, respectively. There are several potential reasons why the recurrent tumors in the nasopharyngeal space, including nasopharyngeal carcinoma stem cells, are not sensitive to radiation and chemotherapy, such as inadequate exposure dose, repopulation of resting stage cells, inaccuracy of target delineation, and unsuitability of radiation treatment plan design; however, further research is needed to obtain a final confirmation. However, for the patients treated with conventional radiotherapy, the most sites of recurrenc is skull base anis the most common site of recurrence in NPC patients treated with conventional radiotherapy [18]; this is reportedly associated with the low dose applied to this region, as a result of the dose limitation to the important organs around the skull base and the dose attenuation in bone [19]. The present study indicated that the skull base the second most common site of recurrence in NPC patients treated with IMRT.
Moreover, our study showed that the most common sites of recurrence in the head and neck lymph nodes include the level II lymph nodes, which is similar to conventional radiotherapy for NPC [20]. This finding was also similar to that observed in the primary lymph node metastasis of NPC-i.e., the level II lymph nodes are the most common sites of invasion in primary NPC [21, 22]. In the present study, there were 2 cases with parotid gland regional lymph node recurrence, which is rare with conventional radiotherapy technology; however, the incidence of parotid gland regional lymph node recurrence has been increasing with the widespread application of IMRT $[23,24]$. One reason for this finding is believed to be the under-dosing of subclinical lesions in the parotid gland, in an attempt at overprotection of the parotid gland, which is adjacent to the parapharyngeal space. Moreover, 4 cases exhibited recurrence in the level I lymph nodes. In general, the invasion rate of level I lymph nodes in primary NPC is low, and level I lymph nodes are considered to represent the routine lymphatic drainage path of NPC [21]. Hence, the recurrence in level I lymph nodes is probably associated with the neck lymphatic block and upstream block caused by pipeline fibrosis after radiotherapy [25].

In the present study, distant metastasis was the main cause of treatment failure in patients with NPC after IMRT; bone, lung, and liver were the most common sites for distant metastases. This result is inevitable following the improvement of local control via IMRT, although the enhancement of the local dose for potentially hidden metastatic lesions would be meaningless during the first visit. The study of Lai et al showed that the changes in radiation technology did not significantly affect the control of distant metastasis in patients with NPC, as observed in patients with NPC treated with IMRT or 2D-RT [26]. With regard to the simultaneous development of primary tumors and metastases, current studies indicate that some tumor cells spread from early tumors or precancerous lesions and form hidden tiny lesions, which subsequently proliferate in suitable local conditions. Hence, the improvement of the detection rate of hidden metastasis via modern imaging techniques and laboratory examination methods would influence the treatment choice of patients with NPC and improve the control of distant metastasis and the prognosis. In our study, we also observed that the 5-year DMFS rates of stage N0, N1, N2, and N3 patients were $95.0 \%, 86.1 \%, 79.5 \%$, and $67.2 \%$ respectively. Thus, with an increase in the $\mathrm{N}$ stage, the DMFS rates significantly decreased, particularly in patients with stage N3 who have poor control of distant metastases. Most studies on NPC patients treated with IMRT have exhibited similar results, and stated that the presence of distant metastasis usually indicates poor prognosis. However, in the future, the manner in which the DMFS rates of NPC patients with late $\mathrm{N}$ stages can be improved will be essential in improving the therapeutic effect. 
Chemotherapy is an effective method for the control of distant metastasis, and may also be involved in radiotherapy sensitization., Concurrent chemotherapy (CCT) has been routinely used in the treatment of locally advanced NPC. In a meta-analysis of clinical research studies on NPC, Zhang et al [27] showed that CCT could improve OS, locoregional control rates, and distant metastasis control rates in locally advanced NPC. However, the conclusion that patients with NPC can benefit from CCT is always based on the results of conventional two-dimensional radiation. At present, the benefits of CCT are unclear in patients with NPC treated with IMRT [28]. Neoadjuvant chemotherapy is considered to be effective for controlling hidden metastatic lesions, although the resultant survival benefit in patients with locally advanced NPC remains controversial. The meta-analysis of Chua et al indicated that, compared with radiotherapy alone, neoadjuvant chemotherapy combined with radiotherapy improved the local control of patients with locally advanced NPC [29]. Moreover, another meta-analysis involving 6 clinical research studies showed that neoadjuvant chemotherapy had no effect on the local control rates of patients with locally advanced NPC [30]. Another meta-analysis on 11 clinical research studies indicated that, compared with concurrent chemoradiotherapy with or without adjuvant chemotherapy, neoadjuvant chemotherapy combined with concurrent chemoradiotherapy failed to yield any survival benefit in patients with NPC [31]. Moreover, we observed that CCT, neoadjuvant chemotherapy, or adjuvant chemotherapy failed to yield any benefit in the OS rate, locoregional control rates, distant metastasis control rate, or PFS rate in NPC patients.

Cox proportional hazards regression indicated that $\mathrm{T}$ stage is a significant risk factor for LRFS and OS, $\mathrm{N}$ stage is a significant risk factor for DMFS and PFS, and age is a significant risk factor for DMFS, OS, and PFS. Based on a study by Sun et al, $\mathrm{T}$ and $\mathrm{N}$ stages are significant risk factors for DMFS, PFS, and DSS in patients with NPC, and that a minimal Gross tumor volume (GTV) dose was a significant risk factor for LRFS [3]. The study of $\mathrm{Ng}$ also indicated that a minimal GTV dose was a significant risk factor for LRFS [32]. As the purpose of the present study was to primarily evaluate the long-term curative effect and summarize the characteristics of survival, no additional dosimetry analysis was required.

In summary, our study finally describes the improved treatment results with IMRT over two dimensional-radiotherapy (2D-RT) are primarily due to the achievement of a higher local tumor control rate and OS rate in NPC patients. Moreover, Although more work is needed to fully elucidate the long-term side-effect, we have determined that distant metastasis is the most commonly observed failure pattern after treatment. These results provide deep insights about the value of IMRT in the treatment and prognosis of NPC patients.

\section{MATERIALS AND METHODS}

\section{Patients}

We enrolled 527 patients with NPC who were treated at the Cancer Hospital of Guangxi Medical University from January 2007 to December 2011, and met the following criteria: histologically confirmed NPC on nasopharyngeal biopsy; no evidence of metastasis; no previous malignancy or other concomitant malignant disease; no previous treatment for NPC; Karnofsky performance status of $\geq 70$; and completion of radical radiotherapy, without any metastasis during the treatment.

The initial work-up included a complete physical examination, computed tomography (CT) or magnetic resonance imaging (MRI) of the head and neck, histological confirmation of nasopharyngeal lesions, chest radiography or $\mathrm{CT}$, abdominal ultrasonography or $\mathrm{CT}$ and single photon emission computed tomography (SPECT) of bone, all of which were used for the exclusion of distant metastases.

The patients included 394 men and 133 women (ratio, 2.9:1), with a median age of 44 years (range, 16-79 years). Patients were staged according to the 2010 Union for International Cancer Control (UICC) staging system. Pathology classification was based on the World Health Organization (WHO) guidelines, with Grade I representing squamous cell carcinoma, Grade II representing non-keratinizing carcinoma, and Grade III representing undifferentiated carcinoma. The baseline data and characteristics of the patients are listed in Table 6.

\section{Radiotherapy and chemotherapy}

All patients were immobilized in the supine position with an individually manufactured precision mask, from the head to the shoulders. Contrast-enhanced CT images were obtained using a CT simulator. After delineation of the target was completed, data were imported into the treatment planning system for treatment design. The prescribed radiation dose to the planning target volume (PTV) including the primary nasopharyngeal gross tumor volume (GTVnx) and involved cervical lymph nodes (GTVnd) was 69.96-74.09 Gy, to the PTV including the high-risk regions (CTV1) was 60-65.1 Gy, and to the PTV including the low-risk regions and neck nodal regions (CTV2) was 51.62-57.6 Gy. IMRT was delivered via 9 fixed-gantry angles with step-and-shoot treatment techniques. All of the patients were treated with 1 fraction daily, for 5 days per week.

During the study period, 468 of the 527 patients received chemotherapy. Of patients with stage II-IVa-b, 41 were treated with radiotherapy alone for economical or personal reasons. Concurrent chemotherapy (CCT) was administered to 112 patients, neoadjuvant chemotherapy (NACT)+CCT was administered to 40 patients, 
Table 6: Characteristics and treatment factors for the entire series of 527 patients

\begin{tabular}{|c|c|c|}
\hline Characteristics & No. of patients & $\%$ \\
\hline \multicolumn{3}{|l|}{ Sex } \\
\hline Male & 394 & 74.8 \\
\hline Female & 133 & 25.2 \\
\hline \multicolumn{3}{|l|}{ Age } \\
\hline$>44$ years & 255 & 48.4 \\
\hline$\leq 44$ years & 272 & 51.6 \\
\hline \multicolumn{3}{|l|}{ Histological type } \\
\hline Non-keratinizing carcinoma & 523 & 99.2 \\
\hline Keratinizing squamous carcinoma & 4 & 0.8 \\
\hline \multicolumn{3}{|l|}{ Tumor stage } \\
\hline $\mathrm{T}_{1}$ & 62 & 11.8 \\
\hline $\mathrm{T}_{2}$ & 156 & 29.6 \\
\hline $\mathrm{T}_{3}$ & 174 & 33.0 \\
\hline $\mathrm{T}_{4}$ & 135 & 25.6 \\
\hline \multicolumn{3}{|l|}{ Node stage } \\
\hline $\mathrm{N}_{0}$ & 60 & 11.4 \\
\hline $\mathrm{N}_{1}$ & 184 & 34.9 \\
\hline $\mathrm{N}_{2}$ & 258 & 49.0 \\
\hline $\mathrm{N}_{3}$ & 25 & 4.7 \\
\hline \multicolumn{3}{|l|}{ Clinical stage } \\
\hline I & 18 & 3.4 \\
\hline II & 111 & 21.1 \\
\hline III & 245 & 46.5 \\
\hline $\mathrm{IV}_{\mathrm{a}-\mathrm{b}}$ & 153 & 29.0 \\
\hline \multicolumn{3}{|l|}{ Chemotherapy } \\
\hline Yes & 468 & 88.8 \\
\hline No & 59 & 11.2 \\
\hline \multicolumn{3}{|l|}{ Concurrent chemotherapy } \\
\hline Yes & 450 & 85.4 \\
\hline No & 77 & 14.6 \\
\hline \multicolumn{3}{|l|}{ Neoadjuvant chemotherapy } \\
\hline Yes & 94 & 17.8 \\
\hline No & 433 & 82.2 \\
\hline \multicolumn{3}{|l|}{ Adjuvant chemotherapy } \\
\hline Yes & 310 & 58.8 \\
\hline No & 217 & 41.2 \\
\hline
\end{tabular}


CCT+adjuvant chemotherapy (AC) was administered to 258 patients, $\mathrm{NACT}+\mathrm{CCT}+\mathrm{AC}$ was administered to 40 patients, and NACT or AC was administered to 18 patients.

Patients received a total of $1-8$ cycles of chemotherapy. The chemotherapy strategy included CCT with cisplatin $\left(100 \mathrm{mg} / \mathrm{m}^{2}\right.$, on day 1 , every 21 days $)$ as well as neoadjuvant chemotherapy and adjuvant chemotherapy with PF (cisplatin [80 mg/m²] on day 1, 5-FU [750 mg/ $\mathrm{m}^{2}$ ] on days $1-4$, civ96h, every 21 days), TP (docetaxel $[60-75 \mathrm{mg} / \mathrm{m}]$ on day 1 , cisplatin $\left[60-80 \mathrm{mg} / \mathrm{m}^{2}\right]$ on day 1, every 21 days), and TPF (cisplatin $\left[60 \mathrm{mg} / \mathrm{m}^{2}\right]$ on day 1 , docetaxel $\left[60 \mathrm{mg} / \mathrm{m}^{2}\right]$ on day $1,5-\mathrm{FU}\left[600 \mathrm{mg} / \mathrm{m}^{2}\right]$ on days $1-5$, civ120h, every 21 days).

\section{Follow-up and evaluation methods}

After the initial treatment, patients were followed up every 3 months during the first 3 years, every 6 months during the next 2 years, and then annually. Chest radiography, abdominal ultrasound, MRI of the nasopharynx and cervical region, and laboratory analysis were performed at each assessment. CT of the chest and abdomen, and SPECT of the entire body were performed every 6 months.

Local recurrence, regional lymph node recurrence, and distant metastasis were confirmed based on pathological examination or imaging findings along with clinical follow-up. SPTs were diagnosed based on the criteria of Warren and Gates [33].

\section{Statistical analysis}

All statistical analyses were performed using the SPSS 22.0 statistical package (SPSS, Chicago, IL). Survival time was calculated from the date of treatment initiation to the date of death or the last follow-up. The $\chi^{2}$ test was performed to assess the associations between metastasis and clinicopathological parameters. The Kaplan-Meier method with a log-rank test was used to calculate the survival rate. To assess the effects of clinicopathological parameters on survival, The Cox proportional hazards regression model was used for univariate and multivariate analyses. Factors were included in univariate analysis as follow: sex, age, clinical stage (T stage, N stage), overall IMRT time, chemotherapy (concurrent chemotherapy, neoadjuvantchemotherapy, adjuvantchemotherapy). All statistical tests were twotailed, and a $\mathrm{P}$ value of $<0.05$ was considered statistically significant.

\section{Abbreviations}

NPC, Nasopharyngeal carcinoma; IMRT, Intensitymodulated radiotherapy; SPT, Secondary primary tumor; OS, overall survival;LRFS, local recurrence-free survival;RRFS, regional relapse-free survival; DMFS, distant-metastatic relaps free survival; PFS, progressionfree survival;2D-RT, two dimensional-radiotherapy; GTV, Gross target volume; PTV, Planned target volume; CCT, Concurrent chemotherapy; NACT, Neoadjuvant chemotherapy; AC, Adjuvant chemotherapy; CT, Computed tomography ; MRI, Magnetic resonance imaging.

\section{ACKNOWLEDGMENTS}

We are grateful to Ying Chen, the head of the Department of Administration and Office of Disease Process for her help during follow-up.

\section{CONFLICTS OF INTEREST}

The authors have no actual or potential conflicts of interest to declare.

\section{GRANT SUPPORT}

This work was supported by a grant from Natural Science Foundation of Guangxi Province (Grant Number: 2013GXNSFBA019199), a grant from National Natural Science Foundation of China (Grant Number: 81260346), and a grant from Guangxi Zhuang Region Health Department (CN) (Grant Number: Z2012346).

\section{REFERENCES}

1. Lee AW, Sze WM, Au JS, Leung SF, Leung TW, Chua DT, Zee BC, Law SC, Teo PM, Tung SY, Kwong DL, Lau WH. Treatment results for nasopharyngeal carcinoma in the modern era: the Hong Kong experience. Int J Radiat Oncol Biol Phys 2005;61:1107-1116.

2. Lee AW, Ng WT, Chan LL, Hung WM, Chan CC, Sze HC, Chan OS, Chang AT, Yeung RM. Evolution of treatment for nasopharyngeal cancer--success and setback in the intensity-modulated radiotherapy era. Radiother Oncol 2014; 110:377-384.

3. Sun X, Su S, Chen C, Han F1, Zhao C1, Xiao W1, Deng X1, Huang S1, Lin C1, Lu T3. Long-term outcomes of intensity-modulated radiotherapy for 868 patients with nasopharyngeal carcinoma: an analysis of survival and treatment toxicities. Radiother Oncol 2014;110:398-403.

4. Zhu XJS. Multivariate Logistic Regression Analysis of the Prognostic Factors for 840 Patients with Nasopharyngeal Carcinoma. Chinese Journal of Clinical Oncology 2008;17:961-966.

5. Yi JL, Gao L, Huang XD, Li SY, Luo JW, Cai WM, Xiao JP, Xu GZ. Nasopharyngeal carcinoma treated by radical radiotherapy alone: Ten-year experience of a single institution. Int J Radiat Oncol Biol Phys 2006;65:161-168.

6. Leung TW, Tung SY, Sze WK, Wong FC, Yuen KK, Lui CM, Lo SH, Ng TY, O SK. Treatment results of 1070 
patients with nasopharyngeal carcinoma: an analysis of survival and failure patterns. Head Neck 2005;27:555-565.

7. Kam MK, Teo PM, Chau RM, Cheung KY, Choi PH, Kwan WH, Leung SF, Zee B, Chan AT. Treatment of nasopharyngeal carcinoma with intensity-modulated radiotherapy: the Hong Kong experience. Int J Radiat Oncol Biol Phys 2004;60:1440-1450.

8. Wolden SL, Chen WC, Pfister DG, Kraus DH, Berry SL, Zelefsky MJ. Intensity-modulated radiation therapy (IMRT) for nasopharynx cancer: update of the Memorial Sloan-Kettering experience. Int J Radiat Oncol Biol Phys 2006;64:57-62.

9. Sham JS, Wei WI, Tai PT, Choy D. Multiple malignant neoplasms in patients with nasopharyngeal carcinoma. Oncology 1990;47:471-474.

10. Teo PM, Chan AT, Leung SF, Chau RM, Yu PK, King WW, Johnson PJ. Increased incidence of tongue cancer after primary radiotherapy for nasopharyngeal carcinoma-the possibility of radiation carcinogenesis. Eur J Cancer 1999;35:219-225.

11. Wang CC, Chen ML, Hsu KH, Lee SP, Chen TC, Chang YS, Tsang NM, Hong JH. Second malignant tumors in patients with nasopharyngeal carcinoma and their association with Epstein-Barr virus. Int J Cancer 2000;87:228-231.

12. Kong L, Lu JJ, Hu C, Guo X, Wu Y, Zhang Y. The risk of second primary tumors in patients with nasopharyngeal carcinoma after definitive radiotherapy. Cancer 2006;107:1287-1293.

13. Lee AW, Ng WT, Chan LK, Chan OS, Hung WM, Chan CC, Cheng PT, Sze H, Lam TS, Yau TK. The strength/ weakness of the AJCC/UICC staging system (7th edition) for nasopharyngeal cancer and suggestions for future improvement. Oral Oncol 2012;48:1007-1013.

14. Chen L, Mao YP, Xie FY, Liu LZ, Sun Y, Tian L, Tang LL, Lin AH, Li L, Ma J. The seventh edition of the UICC/ AJCC staging system for nasopharyngeal carcinoma is prognostically useful for patients treated with intensitymodulated radiotherapy from an endemic area in China. Radiother Oncol 2012;104:331-337.

15. Zong J, Lin S, Lin J, Tang L, Chen B, Zhang M, Zhang Y, $\mathrm{Xu}$ L, Chen Y, Xiao Y, Fang Y, Pan J. Impact of intensitymodulated radiotherapy on nasopharyngeal carcinoma: Validation of the 7 th edition AJCC staging system. Oral Oncol 2015;51:254-259.

16. Kam MK, Chau RM, Suen J, Choi PH, Teo PM. Intensitymodulated radiotherapy in nasopharyngeal carcinoma: dosimetric advantage over conventional plans and feasibility of dose escalation. Int J Radiat Oncol Biol Phys 2003;56:145-157.

17. Li JX, Huang SM, Jiang XH, Ouyang B, Han F, Liu S, Wen BX, Lu TX. Local failure patterns for patients with nasopharyngeal carcinoma after intensity-modulated radiotherapy. Radiat Oncol 2014;9:87.
18. Ng SH, Chang JT, Ko SF, Wan YL, Tang LM, Chen WC. MRI in recurrent nasopharyngeal carcinoma. Neuroradiology 1999;41:855-862.

19. Hsiung CY, Wu JM, Wang CJ, Kuo SC, Yeh SA, Hsu HC, Huang EY. Attenuation of radiation dose by the skull base bone in patients with nasopharyngeal carcinoma: clinical importance. Radiology 2001;218:457-463.

20. Wei WI, Ho WK, Cheng AC, Wu X, Li GK, Nicholls J, Yuen PW, Sham JS. Management of extensive cervical nodal metastasis in nasopharyngeal carcinoma after radiotherapy: a clinicopathological study. Arch Otolaryngol Head Neck Surg. 2001;127:1457-1462.

21. Ho FC, Tham IW, Earnest A, Lee KM, Lu JJ. Patterns of regional lymph node metastasis of nasopharyngeal carcinoma: a meta-analysis of clinical evidence. BMC Cancer 2012;12:98.

22. Tang L, Mao Y, Liu L, Liang S, Chen Y, Sun Y, Liao X, Lin A, Liu M, Li L, Ma J. The volume to be irradiated during selective neck irradiation in nasopharyngeal carcinoma: analysis of the spread patterns in lymph nodes by magnetic resonance imaging. Cancer 2009;115:680-688.

23. Lin DS, Jen YM, Lee JC, Liu SC, Lin YS. Recurrence of nasopharyngeal carcinoma in the parotid region after parotid-gland-sparing radiotherapy. J Formos Med Assoc 2011;110:655-660.

24. Cao CN, Luo JW, Gao L, Yi JL, Huang XD, Wang K, Zhang SP, Qu Y, Li SY, Cai WM, Xiao JP, Zhang Z, Xu GZ. Clinical characteristics and patterns of failure in the parotid region after intensity-modulated radiotherapy for nasopharyngeal carcinoma. Oral Oncol 2013;49:611-614.

25. Fisch UP. Cervical lymph flow in man following radiation and surgery. Trans Am Acad Ophthalmol Otolaryngol 1965;69:846-868.

26. Lai SZ, Li WF, Chen L, Luo W, Chen YY, Liu LZ, Sun Y, Lin AH, Liu MZ, Ma J. How does intensitymodulated radiotherapy versus conventional twodimensional radiotherapy influence the treatment results in nasopharyngeal carcinoma patients. Int J Radiat Oncol Biol Phys 2011;80:661-668.

27. Zhang L, Zhao C, Ghimire B, Hong MH, Liu Q, Zhang Y, Guo Y, Huang YJ, Guan ZZ. The role of concurrent chemoradiotherapy in the treatment of locoregionally advanced nasopharyngeal carcinoma among endemic population: a meta-analysis of the phase III randomized trials. BMC Cancer 2010;10:558.

28. Lin S, Lu JJ, Han L, Pan J. Sequential chemotherapy and intensity-modulated radiation therapy in the management of locoregionally advanced nasopharyngeal carcinoma: experience of 370 consecutive cases. BMC Cancer 2010;10:39.

29. Chua DT, Ma J, Sham JS, Mai HQ, Choy DT, Hong MH, Lu TX, Min HQ.Long-term survival after cisplatinbased induction chemotherapy and radiotherapy for 
nasopharyngeal carcinoma: a pooled data analysis of two phase III trials. J Clin Oncol 2005;23:1118-1124.

30. OuYang PY, Xie C, Mao YP, Zhang Y, Liang XX, Su Z, Liu Q, Xie FY. Significant efficacies of neoadjuvant and adjuvant chemotherapy for nasopharyngeal carcinoma by meta-analysis of published literature-based randomized, controlled trials. Ann Oncol 2013;24:2136-2146.

31. Liang ZG, Zhu XD, Tan AH, Jiang YM, Qu S, Su F, Xu GZ. Induction chemotherapy followed by concurrent chemoradiotherapy versus concurrent chemoradiotherapy with or without adjuvant chemotherapy for locoregionally advanced nasopharyngeal carcinoma: meta-analysis of 1,096 patients from 11 randomized controlled trials. Asian Pac J Cancer Prev 2013;14:515-521.

32. Ng WT, Lee MC, Hung WM, Choi CW, Lee KC, Chan OS, Lee AW. Clinical outcomes and patterns of failure after intensity-modulated radiotherapy for nasopharyngeal carcinoma. Int J Radiat Oncol Biol Phys 2011;79:420-428.

33. Warren S GO. Multiple malignant tumors: a survey of literature and statistical study. Am J Cancer 1932;51:1358-1414. 